\title{
MALINGERING BY PROXY (MBP): AN UNDER-RECOGNIZED FORM OF CHIILDHOOD MALTREATMENT
}

Caroly Pataki MD 1,2 Roxy Szeftel 1,2 Rashelle Hakak PsyD 2 Guiouzel Nabieva MD 1,2 Syed Naqvi MD 1 Michael Couse DO, 2, Erica Lubliner MD, 2

1. Geffen School of Medicine at UCLA; 2. Los Angeles County Department of Mental Health

Introduction: Malingering by proxy (MBP) is a type of maltreatment where a caregiver reports or induces a child to present false or exaggerated symptoms for personal gain. MBP may expose a child to unnecessary medications, and psychological damage can occur when a child is coerced to remain in a "sick role". Rarely studied in children, MBP has an unknown prevalence and appears to be an under recognized problem in the published medical and psychological literature.

Objectives: 1) To present a literature review of childhood MBP

2) To report information from cases of MBP in the Los Angeles San Fernando Child and Family Mental Health Clinic

Methods: 1) PubMed, Google Scholar and MEDLINE search conducted querying for "malingering" and "proxy"

2) Case review of 9 patients with MBP from the Los Angeles San Fernando Child and Family Mental Health Clinic

\section{Results : Literature Review Summary}

- Our search identified only 5 published case reports of childhood psychiatric malingering by proxy (Amlani et al., 2016; Cassar et al., 1996; Roberts, 1997; Lu and Boone, 2002; Russell and Astrue, 2009; Chafetz, 2014. There were also cases reported of malingering by proxy in dogs by dog owners seeking pain medications (Amlani et al., 2016).

- It has been documented that even young children are able to mislead and deceive clinicians by by presenting false reports of symptoms (Walker, 2011)

Table 1. Malingering by Proxy in The Los Angeles San Fernando Child and Family Mental Health Clinic

AGE/SEX CAREGIVER STATED PROBLEM PATIENT CURRENT DIAGNOSIS CAREGIVER GAIN

\begin{tabular}{clll}
\hline $\mathbf{1 8} \mathbf{~ F}$ & Needs medication resumed & $\begin{array}{l}\text { None } \\
\text { Major depression (remitted) }\end{array}$ & SSI Supplemental Security Income \\
\hline $\mathbf{1 2} \mathbf{~ M}$ & Needs medication & Learning Disorder & SSI \\
\hline $\mathbf{8 ~ F}$ & Needs medication for & None & SSI \\
& auditory hallucinations & Anxiety symptoms & Reimbursement for tracheostomy \\
$\mathbf{1 5} \mathbf{M}$ & Intermittent Explosive Disorder & Intellectual Disability & Autism Spectrum Disorder Anxiety support when child doesn't need it \\
\end{tabular}

\begin{tabular}{llll}
\hline $14 \mathbf{~ M}$ & $\begin{array}{l}\text { Needs meds for reported refractory } \\
\text { auditory hallucinations }\end{array}$ & $\begin{array}{l}\text { Autism Spctrum Disorder } \\
\text { No psychosis }\end{array}$ & IHSS In Home Support Services \\
\hline $\mathbf{1 5} \mathbf{F}$ & Needs SSI forms signed & Generalized Anxiety Disorder & $\begin{array}{l}\text { SSI } \\
\text { Home schooling } \\
\text { Mother wants patient to care for her }\end{array}$ \\
$\mathbf{1 1} \mathbf{M}$ & Needs medication & None & SSI \\
$\mathbf{1 4} \mathbf{M}$ & Needs medication & ADHD (Mild) & SSI \\
$\mathbf{8} \mathbf{F}$ & Needs SSI forms signed & Panic Disorder & SSI \\
\hline
\end{tabular}

\section{Conclusions:}

1) It is important for clinicians to recognize MBP in order to protect children from maltreatment.

2) Children with MBP do not initiate malingering but may acquiesce to caregiver directions or needs.

3) Whereas in the dog literature, the secondary gain was pain medication, in our child cases, the secondary gain is almost exclusively financial. None of our cases were post accident or injury whereas some of the reported pediatric cases were.

4) In all our clinic cases, children had a psychiatric illness already treated or remitted, yet parents request additional treatment.

5) Our clinic cases were initially deceptive because of their previous treatment and their return under the false pretense that symptoms had recurred or required additional medication.

6) MBP interfered with the children's appropriate development of autonomy and kept them restricted or at home and "sick" which interrupted their social and overall development. 